\title{
Phosphorus and TSS Removal by Stormwater Bioretention: Effects of Temperature, Salt, and a Submerged Zone and Their Interactions
}

\author{
Laila C. Søberg • Ahmed M. Al-Rubaei • Maria \\ Viklander • Godecke-Tobias Blecken (D)
}

Received: 7 February 2020 / Accepted: 14 May 2020 / Published online: 25 May 2020

(C) The Author(s) 2020

\begin{abstract}
To prevent deterioration of receiving water bodies, phosphorus and total suspended solid (TSS) removal from stormwater is commonly targeted, e.g., by bioretention. However, their removal may vary due to ambient conditions and design features. In this study, the effect of a submerged zone with embedded carbon source (SZC), temperature, and (road) salt on phosphorus removal was investigated using a two-level full factorial design. A sand-based filter material was used. Overall, phosphorus and TSS removal percentages were high. Higher temperature (4.6 vs. $17.1{ }^{\circ} \mathrm{C}$ ) caused higher outflow concentrations, thus lowering removal rates. The presence of salt deteriorated total phosphorus removal, whereas dissolved phosphorus removal was not affected. The impact of the SZC was statistically significant but not regarded to be of practical significance for P removal. In contrast, TSS removal was enhanced by a SZC. The results demonstrated that a relatively simple filter material could provide excellent $\mathrm{P}$ removal, avoiding the need for additives suggested in other studies.
\end{abstract}

Electronic supplementary material The online version of this article (https://doi.org/10.1007/s11270-020-04646-3) contains supplementary material, which is available to authorized users.

L. C. Søberg · A. M. Al-Rubaei · M. Viklander •

G.-T. Blecken $(\triangle)$

Department of Civil, Environmental and Natural Resources Engineering, Urban Water Engineering, Luleå University of Technology, 97187 Lulea, Sweden

e-mail: godble@1tu.se
Keywords Urban hydrology · Stormwater biofilter . Phosphorus · Road salt · Internal water storage ·

Temperature

\section{Introduction}

Urbanization increases stormwater runoff discharges and the amount and variety of nonpoint source pollutants that are transported to receiving waters (Goonetilleke et al. 2005). Nonpoint source pollutants in urban stormwater runoff commonly comprise sediment, nutrients, heavy metals, salts, etc. (Barbosa et al. 2012) and have been identified as one of the main causes of aquatic ecosystem degradation (Walsh et al. 2005).

Among these types of pollutants, phosphorus (P) is commonly detected in urban stormwater runoff ( $\mathrm{Li}$ and Davis 2016; Yang and Toor 2018), which is recognized as a main contributor of $\mathrm{P}$ to receiving waters (Correll 1998). The main sources of $P$ in stormwater runoff include atmospheric deposition, dry deposition of biogenic materials (fallen leaves, pollen, seeds, grass), domestic and agricultural fertilizers, industrial waste, detergents (outside EU and USA, where it has been banned in detergents), lubricants, animal waste, and anthropogenic litter (Berretta and Sansalone 2011; Yang and Toor 2018).

$\mathrm{P}$ is commonly the limiting nutrient in freshwater lakes, reservoirs, streams, and headwaters of estuarine systems (Correll 1998; Yang and Toor 2018). For this reason, excess $\mathrm{P}$ can deteriorate water quality by causing 
eutrophication and related water-quality problems ( $\mathrm{Li}$ and Davis 2016; Yang and Toor 2018).

Thus, stormwater control measures, such as stormwater bioretention facilities, are required for protection of receiving waters in addition to adequate source control. Stormwater bioretention facilities are on-site green infrastructures that aim (inter alia) to improve water quality by harnessing physical straining/ filtration and biochemical/geochemical processes that naturally occur in vegetated filter material (Hunt et al. 2012; Kratky et al. 2017). The flexibility of bioretention facilities in terms of size, design, and appearance enables them to fulfill civil, landscape, and ecological criteria of diverse urban projects (Hunt et al. 2012). Furthermore, bioretention facilities can serve multiple functions, which has enhanced their popularity and made them one of the most commonly applied systems for water quality improvement in urban catchments (Bratieres et al. 2008).

In urban stormwater runoff, $\mathrm{P}$ exists as either dissolved P (DP) (organic P and phosphate species) or particulate $\mathrm{P}$ (Boström et al. 1988; Li and Davis 2016). In bioretention, particulate $\mathrm{P}$ is removed by filtration mechanisms in the filter material, whereas DP is primarily removed by adsorption onto the filter material ( $\mathrm{Li}$ and Davis 2016; Marvin et al. 2020). However, DP can also be removed via plant uptake and microbial immobilization ( $\mathrm{Li}$ and Davis 2016). DP is bioavailable and thus constitutes a greater risk for surface waters than particulate $\mathrm{P}$ (Boström et al. 1988). Most studies to date have only evaluated the removal of $\mathrm{PO}_{4}{ }^{3-}$, which is not equivalent to $\mathrm{DP}\left(\mathrm{PO}_{4}{ }^{3-}\right.$ considered together with other dissolved organic and inorganic forms of $\mathrm{P}$ reflects DP) (Boström et al. 1988; Zhang and Huang 2011). Total P (TP) and $\mathrm{PO}_{4}{ }^{3-}$ removal percentages in stormwater bioretention systems have been shown to range from -398 to $98 \%$ and -1271 to $99 \%$, respectively, independent of design, experimental conditions, and source of inflow (Dietz and Clausen 2005; Bratieres et al. 2008; Hatt et al. 2009; Passeport et al. 2009; Zhang and Huang 2011; Mangangka et al. 2015; Glaister et al. 2017). Nevertheless, the majority of studies have reported TP and $\mathrm{PO}_{4}{ }^{3-}$ removal percentages exceeding $70 \%$, with pilot-scale bioretention systems demonstrating the best results (Blecken et al. 2010; Bratieres et al. 2008; Glaister et al. 2017; Passeport et al. 2009). High DP removal (>97\%) was reported by Zhang and Huang (2011) and Ding et al. (2019). A few studies have reported leaching of TP (Dietz and Clausen 2005; Hatt et al. 2009; Mangangka et al. 2015) and $\mathrm{PO}_{4}{ }^{3-}$ (Hatt et al. 2009; Mangangka et al. 2015; Zinger et al. 2013). Note that the Zinger et al. (2013) study is the only case in which the inclusion of a SZC was shown to adversely affect $\mathrm{P}$ removal.

Even though bioretention facilities have become increasingly popular since their introduction in the $1990 \mathrm{~s}$ and are the focus of increasingly numerous publications (Hunt et al. 2012; Kratky et al. 2017), several distinct knowledge gaps remain. For instance, little is known about how changes in ambient conditions or design modifications affect the ability of bioretention systems to remove certain pollutants (Kratky et al. 2017). One study investigating how changes in temperature influence TP removal found constantly high TP removal in excess of $90 \%$ (Blecken et al. 2010). In their study, no significant differences between the three tested temperatures 2,7 , and $20^{\circ} \mathrm{C}$ were detected. Similarly, Valtanen et al. (2017) reported constantly high P removal by bioretention systems in Southern Finland despite seasonal changes in temperature, even though TP sorption rates have previously been shown to increase at higher temperatures (Kratky et al. 2017). Salt-laden stormwater may influence TP removal as Szota et al. (2015) reported a significant decrease in outflow $\mathrm{P}$ concentrations with increasing salt concentrations. In contrast, Valtanen et al. (2017) did not find any significant differences between systems exposed to or not exposed to salt. Given the small number of such studies and partly contradictory results, further investigations are needed to verify these results.

Research on the effect of various bioretention design features on P removal has so far mainly focused on filter materials since leaching of $P$ from unsuitable materials has been identified as a problem (e.g., due to wash out of fines or decay of organic materials, such as compost, peat, or mulch; Hunt et al. 2006; Chahal et al. 2016; Marvin et al. 2020). Since a high percentage of $P$ in stormwater is particle-bound, TP outflow concentrations are often correlated with total suspended solid (TSS) outflow concentrations (Blecken et al. 2010). In general, a filter material with only a small fraction of fines and organic matter is recommended. Based on the assumption that a "standard" filter material may not provide sufficient $P$ removal, various amendments, such as (inter alia) fly ash, expanded shale, biochar, pumice, iron filings, or iron wool, have been suggested to increase $\mathrm{P}$ sorption capacities and, thus, removal (Zhang et al. 2008; Li et al. 2018; Cheng et al. 2018; Erickson et al. 
2012; Iqbal et al. 2015) as summarized in the recent review by Marvin et al. (2020). Another design feature that has been shown to enhance P removal is a submerged zone (which has mainly been developed to enhance nitrogen removal; Dietz and Clausen 2006). For instance, Zhang and Huang (2011) and Glaister et al. (2017) reported significantly higher removal of TP and DP when a SZC was used. However, in contrast to filter materials, only a few studies have evaluated this topic and evidence for how inclusion of a submerged zone affects $P$ removal is still limited.

Another limitation of many of the studies cited above is they often focused on the effect of only a single factor, thus, neglecting probable interactions. The work presented here aims to clarify how a submerged zone and changes in ambient conditions (temperature, salt-laden stormwater) and their interactions influence the ability of bioretention systems to remove P. Given the potential correlation of $\mathrm{P}$ and TSS concentrations in bioretention outflow, TSS was also included in this study.

\section{Materials and Methods}

\subsection{Pilot-Scale Experiments}

Pilot-scale bioretention columns were used to study P removal from semi-synthetic urban stormwater runoff. The columns (height: $900 \mathrm{~mm}$ ) were constructed from polyvinyl chloride (PVC) pipes (inner diameter: $380 \mathrm{~mm}$ ) with sandblasted inner walls to prevent preferential flow. A ponding zone (height: $400 \mathrm{~mm}$, made from transparent plexiglas) was attached as an extension of the pipe to provide light for plant growth. Figure 1 provides a schematic of the column design.

The filter material consisted of four layers:

- Top layer (height: $400 \mathrm{~mm}$ ): a mixture containing $25 \% 0.2-0.5 \mathrm{~mm}$ dried sand, $25 \% 0.5-1.0 \mathrm{~mm}$ dried sand, 25\% 1.0-2.0 mm dried sand, 10\% 2.0-4.0 mm dried sand, and $15 \%$ topsoil $\left(D_{50}=0.9 \mathrm{~mm}\right.$, coefficient of uniformity $C_{\underline{u}}=3.7 \mathrm{~mm}$, coefficient of curvature $C_{\mathrm{C}}=0.8$, soil organic matter content $=13.1 \mathrm{~g}$ $\mathrm{OM} / \mathrm{kg} \mathrm{DM}$ ).

- Bottom filter layer (height: $400 \mathrm{~mm}$ ): $0.2-0.5 \mathrm{~mm}$ dried sand.

- Transition layer (height: $30 \mathrm{~mm}$ ): $1.0-2.0 \mathrm{~mm}$ dried sand.
- Drainage layer (height: $70 \mathrm{~mm}$ ): $2.0-4.0 \mathrm{~mm}$ dried sand.

The filter material was a sand-based material partly according to recommendations from the Facility for Advancing Water Biofiltration (FAWB 2008). However, to enhance infiltration during freeze-thaw cycles (Zhao and Gray 1999), the filter material was adapted to colder climate conditions by including a lower proportion of fine fractions. The material was previously tested for P removal by Blecken et al. (2010), who observed high TP removal (exceeding 90\%) from stormwater containing $0.31 \pm 0.01 \mathrm{mg} / \mathrm{L}$ TP.

The transition layer was used to prevent wash out of the filter material and clogging of the collection pipe. A drainage pipe (diameter $54 \mathrm{~mm}$ ) was embedded in the drainage layer to divert water to a sampling outlet. The bioretention columns with a water-saturated submerged zone with carbon source (SZC) were designed with an increased outlet (height: $450 \mathrm{~mm}$ ). These columns included $800 \mathrm{~g}$ of cellulose-based carbon source (pine and spruce wood shavings) mixed randomly into the bottom layer, corresponding to a soil organic matter content (by weight) of $1 \%$.

The columns were planted with native wet/droughttolerant plants adapted to Northern European climates. Three Juncus conglomeratus, two Phalaris arundinacea, and two Carex panicea were randomly planted in each column, corresponding to a plant density of 64 plants $/ \mathrm{m}^{2}$. After planting, the columns were stored outside and watered twice weekly with unchlorinated tap water for 3 months to enable plant establishment. Afterwards, half of the columns, with an even distribution of standard columns (bottom outlet) and columns with a SZC, were placed in an indoor laboratory (Fig. 1), whereas the other half were placed in a refrigerated container. Both environments had near-constant air temperatures of $17.1 \pm 1.5^{\circ} \mathrm{C}$ and $4.6 \pm 0.6^{\circ} \mathrm{C}$, respectively (measured with Microlite II External USB Temp loggers). After the columns had been moved inside, continuous plant growth was ensured by illuminating the columns for $12 \mathrm{~h}$ every day with high-pressure sodium greenhouse lamps (G-power Agro, $400 \mathrm{~W}, 55,000 \mathrm{Lm}$ ), which were placed approximately $70 \mathrm{~cm}$ above the transparent top of the columns. One lamp each was used to light 12 columns, which were placed on an area of approximately $3 \mathrm{~m}^{2}$ (Fig. 1). The columns were watered twice weekly with unchlorinated tap water for another 3 months to ensure column maturity before stormwater 

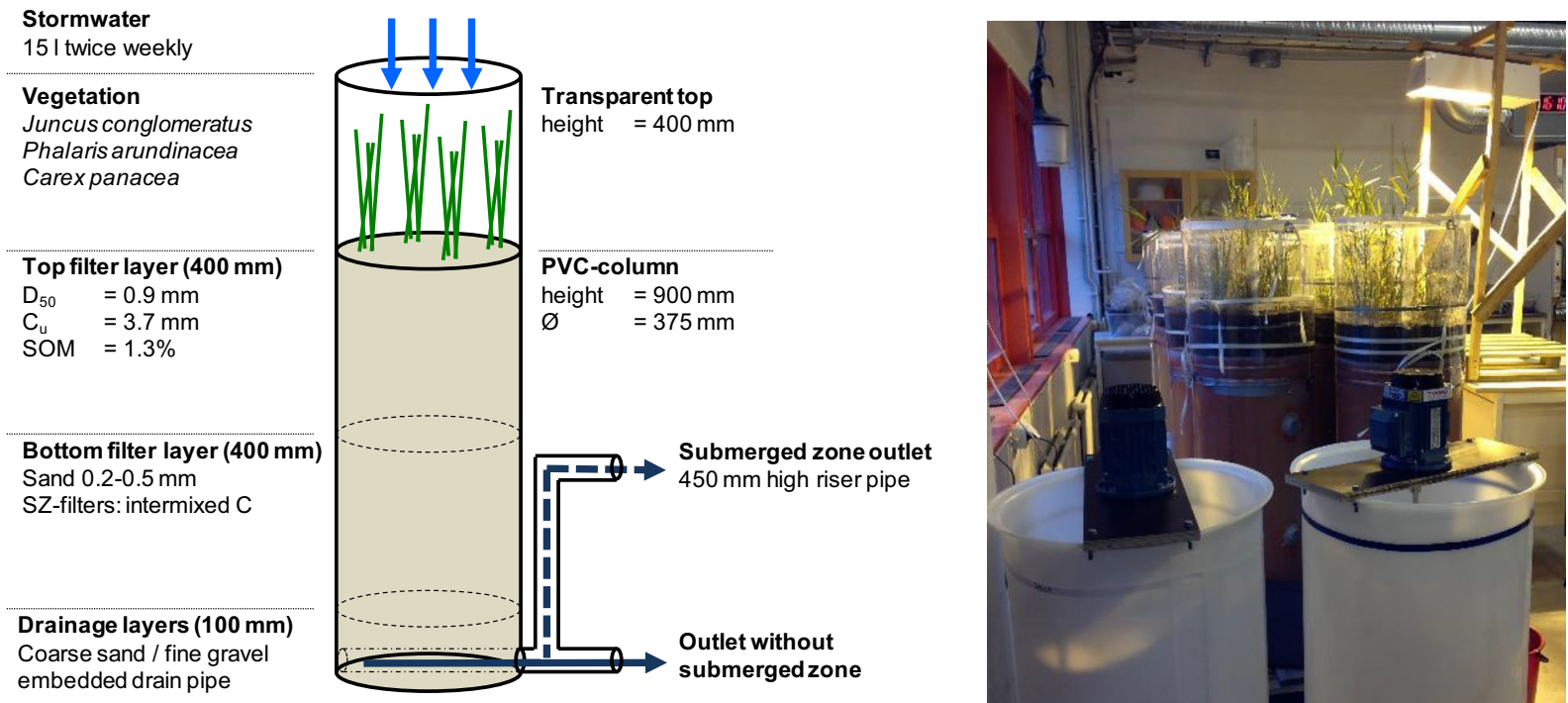

Fig. 1 Left: Bioretention column design, filter material characteristics, and vegetation details. Right: Columns in the laboratory (warm temperature) with greenhouse lamp. Tanks for stormwater

was added. After this establishment period, the plants had grown to a height of approximately $60 \mathrm{~cm}$ (Phalaris arundinacea) and 30-40 cm (Juncus conglomeratus and Carex panacea). Thus, the plant's status corresponded to summer conditions in temperate (e.g., northern European) climates.

\subsection{Experimental Design}

TP, DP, TSS, and $\mathrm{Cl}^{-}$concentrations in inflow and outflow were analyzed in bioretention columns with or without a SZC $(0 \mathrm{~mm}$ and $450 \mathrm{~mm})$ that had been exposed to high or low temperature $\left(17.1^{\circ} \mathrm{C}\right.$ and $4.6{ }^{\circ} \mathrm{C}$, respectively) and dosed with stormwater with or without salt addition. This resulted in a three-factor, two-level full factorial design of experiment with eight different experimental combinations (Table 1). All combinations were tested in triplicate.

\subsection{Stormwater Preparation and Dosing}

For 18 weeks, the columns were dosed twice weekly with $15 \mathrm{~L}$ of semisynthetic stormwater (i.e., 135-mm water column on top of the bioretention system, which, for instance, approximately corresponds to a $5.5-\mathrm{mm}$ storm assuming that the bioretention area is $4 \%$ of the contributing impervious catchment area). The semisynthetic stormwater prepared by adding natural stormwater sediment (originating from a stormwater preparation in the foreground. The installation in the refrigerated container was similar

gully pot) to unchlorinated tap water. Laboratory-grade chemicals were added to achieve target pollutant concentrations (Table 2). NaCl (de-icing salt, AkzoNobel, Amsterdam, Netherlands) was added to half of the stormwater to achieve a concentration of approximately $2000 \mathrm{mg} \mathrm{Cl}^{-} / \mathrm{L}$. For more detailed information, see Søberg et al. (2017), in which the metal removal results from this experiment are published.

The stormwater was prepared separately for each temperature (high and low) at least $48 \mathrm{~h}$ before dosing and continuously mixed during that time to allow temperature adjustment and ensure homogeneity before dosing.

\subsection{Sampling Procedure}

Grab samples of the semi-synthetic stormwater were taken prior to each dosing event from each mixture (Table 2) and stored in acid-washed PVC bottles.

Outflow samples were collected separately from each bioretention column after every sixth event (i.e., after 3 , $6,9,12,15$, and 18 weeks of experimental run time). After watering, the columns were allowed to drain overnight into acid-washed transparent polyethylene (PE) tanks in which the total effluent was collected. From this total outflow volume, grab sub-samples were taken, while the collected water was stirred. Therefore, these grab samples represented the outflow water from a respective event. First, samples used for $\mathrm{P}$ analysis were 
Table 1 Experimental combinations

\begin{tabular}{llll}
\hline Temperature $\left({ }^{\circ} \mathrm{C}\right)$ & Salinity $\left(\mathrm{g} \mathrm{L}^{-1}\right)$ & Submerged zone $(\mathrm{mm})$ & Replicates \\
\hline 4.6 & $<0.05$ & 450 & 3 \\
4.6 & 2 & 450 & 3 \\
4.6 & $<0.05$ & 0 & 3 \\
4.6 & 2 & 0 & 3 \\
17.1 & $<0.05$ & 450 & 3 \\
17.1 & 2 & 450 & 3 \\
17.1 & $<0.05$ & 0 & 3 \\
17.1 & 2 & 0 & 3 \\
\hline
\end{tabular}

collected in 125-mL acid-washed PE bottles, and then samples used to measure TSS were collected in 2-L PE bottles.

\subsection{Sample Analysis}

Water samples were analyzed for TP, DP, TSS, and $\mathrm{Cl}^{-}$. The $\mathrm{P}$ and $\mathrm{Cl}^{-}$analyses were carried out by a commercial laboratory (ALS Scandinavia AB, Luleå, Sweden) accredited by the national accreditation body for Sweden SWEDAC using US EPA Method 200.7 (ICPAES) and CSN EN ISO 10304-1, respectively. For TP and DP, the detection limits were $10 \mu \mathrm{g} / \mathrm{L}$ and $1 \mu \mathrm{g} / \mathrm{L}$, respectively. TSS was determined by filtration through $1.6-\mu \mathrm{m}$ filters, and the detection limit was $2 \mathrm{mg} / \mathrm{L}$.

\subsection{Data Analysis}

All data were tested for time trends, homogeneity of variance, and normal distribution (Anderson-Darling test and goodness-of-fit test). Datasets were found to be normally distributed. No time trend was detected; i.e., the repeated samplings were considered as replicates.
For TSS and P, a three-factor, two-level full factorial design of experiment (DOE) analysis was conducted to assess how the three tested factors (temperature, salt, and SZC) and their two-way interactions affected outflow concentrations. The model analyzed the data based on changes that occurred as each factor was varied from low to high. If concentrations were below the detection limit, the detection limit was used in the statistical analysis. Thus, over-estimation of the bioretention treatment performance was avoided.

\section{Results}

\subsection{Outflow Concentrations and Removal}

Depending on the pollutant, outflow concentrations varied among the examined factors and design configurations (Table 3). Still, TSS and P outflow concentrations (Table 3) were always significantly lower than the corresponding high inflow concentrations (Table 2). Thus, the removal percentage in most cases exceeded 80 $90 \%$.

Table 2 Characteristics of the semi-synthetic stormwater

\begin{tabular}{|c|c|c|c|c|c|c|}
\hline Factors & Target conc. & & & & & \\
\hline Temp. $\left({ }^{\circ} \mathrm{C}\right)$ & & 17.1 & 17.1 & 4.6 & 4.6 & \\
\hline Salt & & + & - & + & - & \\
\hline Pollutant & & Mean inflow & itration (SD & & & Source \\
\hline $\mathrm{TP}$ & 350 & 380 (138) & $374(120)$ & 410.5 (139.7) & $371.9(106.2$ & $\mathrm{KH}_{2} \mathrm{PO}_{4}$ \\
\hline DP & & $108.7(64.9)$ & $92(24.5)$ & $94.8(21.8)$ & $83.8(24.8)$ & \\
\hline $\mathrm{Cl}^{-}$ & 0 and 2000 & 2241 (239) & $47(7)$ & $2253(232)$ & $45(7)$ & $\mathrm{NaCl}$ \\
\hline TSS & 150 & $131(48)$ & $127(39)$ & 128 (19) & $122(15)$ & GPS $^{\mathrm{a}}$ \\
\hline
\end{tabular}

SD standard deviation in parentheses; TP and DP: $\mu \mathrm{g} \mathrm{L}^{-1} ; \mathrm{Cl}^{-}$and TSS: $\mathrm{mg} \mathrm{L}^{-1}$

${ }^{\text {a }}$ Gully pot sediment $(\leq 500 \mu \mathrm{m})$ 
TSS effluent concentrations were nearly always below the detection limit of $2 \mathrm{mg} / \mathrm{L}$ for the SZC columns, resulting in a removal of $98 \%$ or higher. The bioretention columns without a SZC showed higher TSS outflow concentrations up to about $20 \mathrm{mg} / \mathrm{L}$ (Fig. 2; Table 3).

No significant correlations between TSS and both DP and TP concentrations were observed.

$\mathrm{Cl}^{-}$was not retained in the bioretention columns since outflow concentrations were in the same range as inflow concentrations (Tables 2 and 3).

\subsection{Main Effects and Interactions}

This section describes how the tested factors affected $\mathrm{P}$ and TSS outflow concentrations, and thus removal. Figure 2 shows outflow concentrations for the different factor combinations presented in Table 3, whereas Table 4 presents the significance of the factors and their two-way interactions. This information is supported by the supplementary material, which presents the main effects and interaction plots derived from analysis of the factorial design (Supplementary Figure 1) and pareto charts illustrating the significance of the factors (Supplementary Figure 2).

Temperature Temperature generally affected bioretention column performance toward $\mathrm{P}$ removal and had the greatest impact of all the tested factors on outflow concentrations of P (Table 4). High temperature significantly increased $\mathrm{P}$ outflow concentrations and hence deteriorated $\mathrm{P}$ removal (Fig. 2; Table 4;
Supplementary Figure 1). TSS treatment was not significantly affected by temperature.

Salt Salt generally deteriorated bioretention column performance toward TP removal. The addition of salt significantly increased outflow concentrations (Table 4) and hence significantly lowered removal. DP treatment was not significantly affected by salt. The statistically significant effect of salt on TSS outflow concentrations was judged to have no practical significance (Table 4; Supplementary Figure 1).

Submerged Zone Including a SZC in the bioretention columns significantly lowered TP outflow concentrations (Table 4; Supplementary Figure 1) and hence significantly increased removal. However, use of a SZC affected TP removal the least of all main factors. Also, the SZC did not significantly affect DP outflow concentrations (Table 4).

In contrast, inclusion of a SZC had the most significant effect on TSS outflow concentrations of all main factors. Standard columns without a SZC showed outflow concentrations varying from approximately 3 to $15 \mathrm{mg} / \mathrm{L}$, whereas columns with a SZC showed outflow concentrations below or close to the detection limit of $2 \mathrm{mg} / \mathrm{L}$. The latter finding indicates excellent removal of TSS regardless of changes in salt content or ambient temperature.

Temperature $\times$ Submerged Zone The interaction between temperature and a SZC significantly affected TP outflow concentrations (Table 4). The inclusion of a SZC was beneficial at low temperature but significantly

Table 3 Mean outflow concentrations of TP, DP, TSS, and $\mathrm{Cl}^{-}$( \pm standard deviation)

\begin{tabular}{|c|c|c|c|c|c|c|c|c|c|}
\hline \multicolumn{10}{|c|}{ Factor combination } \\
\hline Temperature & ${ }^{\circ} \mathrm{C}$ & 4.6 & 17.1 & 4.6 & 17.1 & 4.6 & 17.1 & 4.6 & 17.1 \\
\hline Salt & With/without & - & - & + & + & - & - & + & + \\
\hline $\mathrm{SZC}$ & $\mathrm{mm}$ & 0 & 0 & 0 & 0 & 450 & 450 & 450 & 450 \\
\hline \multicolumn{10}{|l|}{ Pollutant } \\
\hline $\mathrm{Cl}^{-}$ & $\mathrm{mg} / \mathrm{L}$ & $43 \pm 4$ & $50 \pm 6$ & $2123 \pm 155$ & $2307 \pm 232$ & $44 \pm 3$ & $50 \pm 5$ & $2175 \pm 125$ & $2247 \pm 190$ \\
\hline \multirow[t]{2}{*}{ ТP } & $\mu \mathrm{g} / \mathrm{L}$ & $34.7 \pm 12.2$ & $38.3 \pm 20.5$ & $38.1 \pm 10.4$ & $62.9 \pm 13.3$ & $17.4 \pm 4.7$ & $39 \pm 14.8$ & $18.7 \pm 6.2$ & $67.6 \pm 15.2$ \\
\hline & Removal \% & $91 \pm 4$ & $88 \pm 9$ & $90 \pm 3$ & $77 \pm 17$ & $95 \pm 3$ & $88 \pm 7$ & $95 \pm 4$ & $73 \pm 24$ \\
\hline \multirow[t]{2}{*}{ DP } & $\mu \mathrm{g} / \mathrm{L}$ & $4.6 \pm 2.3$ & $8 \pm 4.9$ & $4 \pm 0.6$ & $9.4 \pm 4.2$ & $3.6 \pm 0.9$ & $11.1 \pm 5.6$ & $4.7 \pm 1.5$ & $9.8 \pm 5.9$ \\
\hline & Removal \% & $93 \pm 8$ & $88 \pm 14$ & $96 \pm 1$ & $86 \pm 13$ & $97 \pm 3$ & $88 \pm 5$ & $95 \pm 3$ & $89 \pm 6$ \\
\hline \multirow[t]{2}{*}{ TSS } & $\mathrm{mg} / \mathrm{L}$ & $7.0 \pm 1.1$ & $4.3 \pm 0.7$ & $5.9 \pm 0.9$ & $10.5 \pm 1.6$ & $<2.0$ & $<2.0$ & $2.1 \pm 0.1$ & $2.3 \pm 0.2$ \\
\hline & Removal \% & $94 \pm 1$ & $95 \pm 1$ & $94 \pm 1$ & $90 \pm 1$ & $>98$ & $>98$ & $98 \pm 0$ & $98 \pm 0$ \\
\hline
\end{tabular}



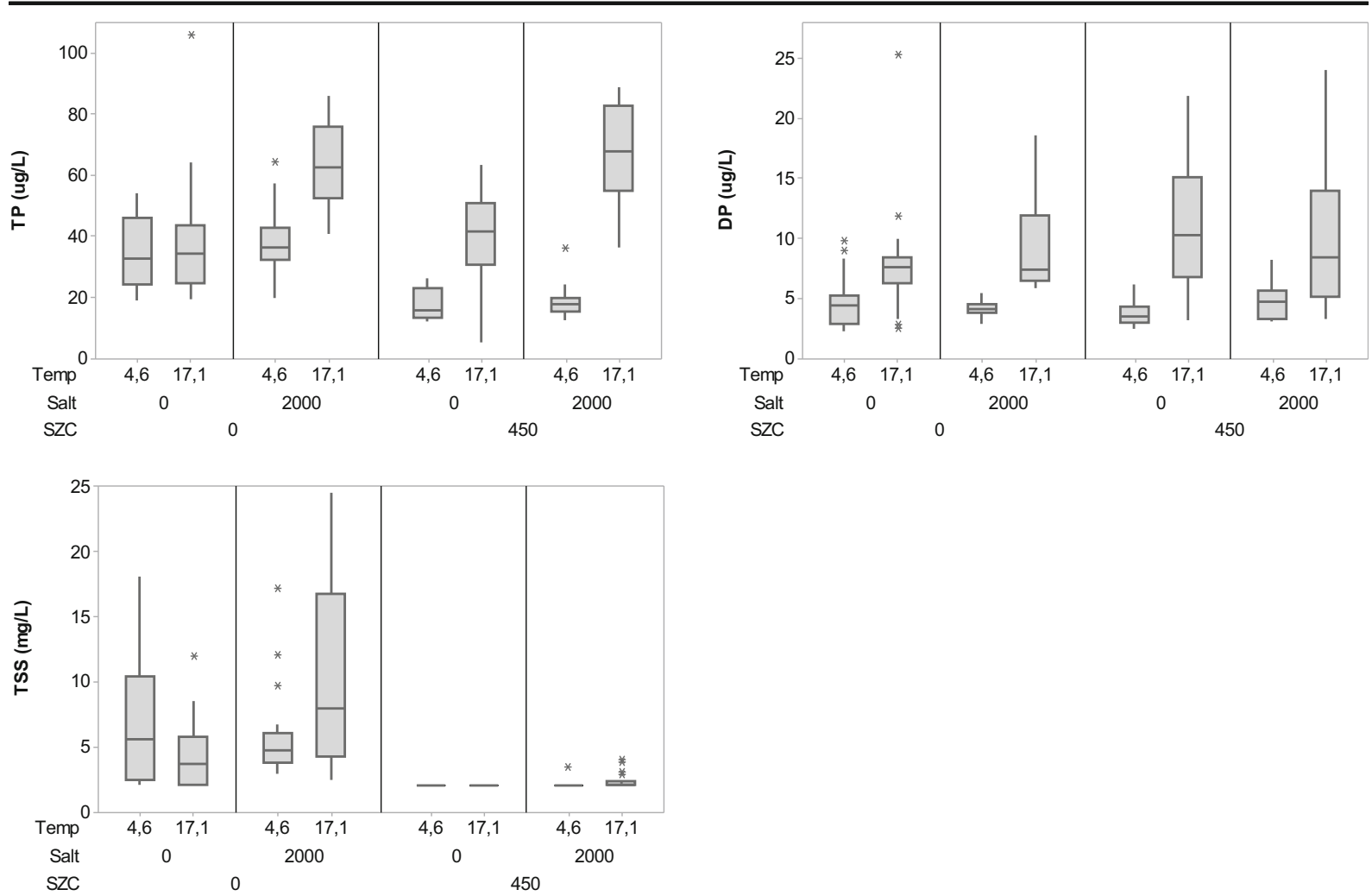

Fig. 2 Box plots of TP, DP, and TSS outflow concentrations for the different factor combinations. TSS detection limit $=2 \mathrm{mg} / \mathrm{L}$. The boxes indicate the interquartile range (IQR), the whiskers

extend to $1.5 \mathrm{IQR}$, and outliers are indicated by an asterisk. Note the different scales of $y$-axes

increased TP outflow concentrations at high temperature (Fig. 2).

Temperature $\times$ Salt The interaction between salt and temperature significantly affected outflow concentrations of TP (Table 4). The addition of salt to inflow water did not cause any differences in the outflow concentrations of TP at low temperature, but the presence of salt significantly increased TP outflow concentrations at high temperature (Supplementary Figure 1).

\section{Discussion}

\subsection{Total Suspended Solids}

TSS was efficiently retained in all of the bioretention columns independently of design and ambient conditions, with the mean removal percentage surpassing $90 \%$ for the standard columns and $98 \%$ for the SZC- bioretention columns. These observed removal percentages agree well with previous studies using lab- and pilot-scale bioretention columns (Lau et al. 2000; Hsieh and Davis 2005; Bratieres et al. 2008; Blecken et al. 2010), which demonstrated removal percentages in excess of $90 \%$ irrespective of experimental setup and design.

The positive effect that the SZC had on TSS outflow concentrations was regarded to be of practical significance since the TSS outflow concentrations from the SZC columns were always below or around the detection limit $(2 \mathrm{mg} / \mathrm{L})$. In contrast, TSS concentrations in the effluent from the standard columns varied far more and reached (despite high removal percentages) up to approximately $20 \mathrm{mg} / \mathrm{L}$. Enhanced TSS removal in bioretention with a submerged zone has also been observed by, e.g., Li et al. (2014). Li et al. (2014) hypothesizes that reasons are less re-suspension of fines and less formation of macropores in bioretention with SZ and, thus, less preferential flow paths, which enable particles to move through the filter. 
Table 4 Summary of the effects of the examined factors together with the significance and importance of these effects on TSS and P outflow concentrations. Importance was determined based on pareto effect charts. The direction of each effect was determined from factorial plots and effect coefficients from regression models. $\uparrow$ : increase; $\downarrow$ : decrease; (x): importance of an effect, where $\mathrm{x}$ is a number from 1 (largest impact) to 6 (smallest impact); n.s.: not significant. Pareto charts of these models are presented in Supplementary Figure 2

\begin{tabular}{lllll}
\hline Factors & & TP & DP & TSS \\
\hline SZC & Effect & $\downarrow(5)$ & n.s. & $\downarrow(1)$ \\
& $P$ & 0.001 & & 0.000 \\
Temp. & Effect & $\uparrow(1)$ & $\uparrow(1)$ & n.s. \\
& $P$ & 0.000 & 0.000 & \\
Salt & Effect & $\uparrow(2)$ & n.s. & $\uparrow(4)$ \\
& $P$ & 0.000 & & 0.049 \\
SZC $\times$ Temp. & Effect & $(4)$ & n.s. & n.s. \\
& $P$ & 0.000 & & \\
SZC $\times$ Salt & Effect & n.s. & n.s. & $(3)$ \\
& $P$ & & & 0.047 \\
Temp. $\times$ Salt & Effect & $(3)$ & n.s. & $(2)$ \\
& $P$ & 0.000 & & 0.002 \\
$R^{2}($ adj. $)(\%)$ & & 60.7 & 31.7 & 36.3 \\
\hline
\end{tabular}

The other factors and interactions had, despite their statistical significance, only little or no practical significance for TSS outflow concentrations.

Surprisingly, salt did not have a distinct effect on TSS outflow concentrations from the stormwater bioretention columns, in contrast to previous research showing salt was associated with high TSS outflow concentrations in stormwater control measures (Winston et al. 2016; McManus and Davis 2017). The latter effect was explained by increased soil dispersion due to ion exchange with other cations by $\mathrm{Na}^{+}$(Winston et al. 2016; McManus and Davis 2017). One reason for the small impact of salt in the present study could be the chosen filter material, which had a very low percentage of fines and organic matter content. Further, the salt concentrations in the stormwater were far lower than those reported by McManus and Davis (2017).

The efficient removal of TSS suggests that the tested bioretention designs could also efficiently remove particle-associated pollutants. However, in contrast to, e.g., Blecken et al. (2010), in this study, no correlation between TP and TSS outflow concentrations was observed.

\subsection{Phosphorus}

The outflow concentrations of both TP and DP from the stormwater bioretention columns were always significantly lower than inflow concentrations, with removal percentages of TP and DP always exceeding 74 and $84 \%$, respectively, independently of ambient conditions and design. This is in line with many previous pilot- and field-scale stormwater bioretention studies reporting mean TP removal percentages above 70\% (Davis et al. 2006; Bratieres et al. 2008; Blecken et al. 2010; Zhang and Huang 2011; Glaister et al. 2017). Further, no leaching (as reported by Dietz and Clausen (2005), Hatt et al. (2009), and Mangangka et al. (2015)) was observed. Thus, the general bioretention design and filter material used in this study enabled sufficient $P$ removal, and thus, the effect of the evaluated factors was far smaller than in other studies where results involved both leaching and efficient removal (e.g., Hatt et al. 2009). Plant growth significantly affects P removal (e.g., Glaister et al. 2017). The well-established plants may have contributed to the efficient TP and DP removal. However, since plant growth and/or activity was not measured in the present study, this assumption remains hypothetical.

DP has only been investigated in a few previous studies. Zhang and Huang (2011) reported a mean removal of $99 \%$. However, mean removals above $70 \%$ have been reported for $\mathrm{PO}_{4}{ }^{3-}$ (Bratieres et al. 2008; Passeport et al. 2009; Hatt et al. 2009; Glaister et al. 2017), which together with other dissolved organic and inorganic forms of P constitutes DP (Boström et al. 1988; Zhang and Huang 2011). Hence, previous studies corroborate the observed DP results.

Of all the factors studied, only temperature significantly affected DP, with outflow concentrations increasing as the temperature increased. However, DP outflow concentrations were poorly described by the two-level full factorial regression analysis $\left(R^{2}(\operatorname{adj})=31.7 \%\right)$. As such, factors other than the ones tested probably influenced DP removal. On the other hand, TP removal was significantly affected by SZC inclusion, temperature, and salt-laden inflow, as well as interactions between temperature and salt-laden inflow and temperature and the SZC.

Similar to the findings for DP, higher temperatures also caused significantly higher outflow concentrations of TP. However, previous studies of $\mathrm{P}$ adsorption onto soil have reported a positive correlation between 
temperature and $\mathrm{P}$ adsorption (Barrow 1979; Zhang et al. 2011; Bai et al. 2017). Furthermore, Blecken et al. (2010), who used a similar column set-up and filter material as in the present study, found no differences in TP removal between standard bioretention columns exposed to ambient temperatures of 2,7 , and $20^{\circ} \mathrm{C}$. They explain the high removal independent of temperature with physical filtration of (mainly) particulate $\mathrm{P}$ by bioretention. Hence, more research is needed to understand how seasonal changes in temperature might affect $\mathrm{P}$ removal by stormwater bioretention systems.

Findings on the effect of salt-laden stormwater on TP removal by bioretention are inconsistent. In our study, inflow with salt caused significantly higher outflow concentrations of TP compared to inflow without salt and hence had a negative effect on TP removal. In contrast, Szota et al. (2015) reported a significant decrease of outflow P concentrations with increasing salt concentration resulting in enhanced removal, while Valtanen et al. (2017) did not find any significant effects of salt on TP removal in pilot-scale stormwater bioretention systems. However, studies on P adsorption in soils and sediments found that $\mathrm{P}$ adsorption decreases as salinity increases (Zhang and Huang 2011; Bai et al. 2017), corroborating our findings. In summary, studies on salt influence on P removal in bioretention are partly contradictory and further research (including conducted in the field) is suggested.

McManus and Davis (2017) and Winston et al. (2016) have reported significantly higher TSS outflow concentrations when stormwater contains road salt, which could also involve higher concentrations of (particulate) P. This was not observed in our study, as discussed above for TSS.

Salt is recognized as one of the main factors influencing $\mathrm{P}$ adsorption-desorption processes in soil (Liu et al. 2002; Jun et al. 2013). The negative effect of salt has been explained by competition for binding sites between negatively charged ions and $\mathrm{PO}_{4}{ }^{3-}$ (Liu et al. 2002). However, this does not explain the findings in the present study since salt-laden inflow only affected TP and not DP $\left(\mathrm{PO}_{4}{ }^{3}\right)$.

Furthermore, combination of high temperature and salt-laden inflow significantly increased TP outflow concentrations compared to low-temperature conditions either with or without the presence of salt. It is important to note that the negative effects of high temperature and salt were enhanced when these two factors affected the bioretention column simultaneously.
The more effective removal of DP compared to TP might be explained by increased $\mathrm{PO}_{4}{ }^{3-}$ precipitation at higher temperatures (Reddy and DeLaune 2008); i.e., the proportion of TP increases as more $\mathrm{PO}_{4}{ }^{3-}$ reacts with other compounds to form solid minerals. However, precipitation is also positively correlated with salinity (Remmen et al. 2017). Hence, salt-laden inflow should have had a decreasing effect on outflow concentrations of DP and not only an increasing effect on TP. The effective DP removal also shows that $\mathrm{P}$ removal is not only attributed to trapping of sediments (and therewith associated TP).

Inclusion of a SZC significantly decreased TP outflow concentrations and hence benefitted removal. Previous studies have reached similar conclusions (Zhang and Huang 2011; Glaister et al. 2017). The results of Zhang and Huang (2011) are similar to the present study. Although a SZC significantly increased P removal, all filters (both with and without a SZC) showed TP and DP removal exceeding $92 \%$. In the present study, the effect of the SZC was slightly higher, but still the standard columns performed well (Table 3 ). In contrast, Zinger et al. (2013) identified an opposite effect for bioretention columns with a SZC. Glaister et al. (2017) related the beneficial effect of a SZC on P removal to plant well-being and the plant's positive effect on $\mathrm{P}$ removal, whereas Zinger et al. (2013) attributed the negative effect of a SZC to the remobilization of finegrained sediment from the filter material containing $\mathrm{P}$. However, $\mathrm{P}$ adsorption decreases under anoxic conditions (Nürnberg 1984; Mucci et al. 2018). Hence, a SZC should increase TP outflow concentrations. In the present study, this effect was observed when bioretention columns with a SZC were exposed to high temperatures, although it should be emphasized that the difference in TP removal between bioretention columns with and without a SZC was relatively small. Thus, the identified beneficial effect of a SZC on TP removal has limited practical significance.

Nevertheless, TP and DP removal percentages always exceeded 74 and $84 \%$, respectively. Thus, the observed negative effects of high temperature and saltladen inflow - as well as the positive effect of including a SZC — should not be overemphasized.

There have been many reports of leaching of $\mathrm{P}$ from newly installed bioretention facilities due to wash out of fines from the filter material (Dietz and Clausen 2005; Hsieh et al. 2007; Blecken et al. 2007). Such leaching or a time trend was not observed in this study. One reason 
may be the use of a coarser filter material containing less fines. Blecken et al. (2007), who used a similar filter material to that in the present study, reported that $\mathrm{P}$ outflow concentrations were relatively stable after 2 months' establishing time and 1 month's stormwater dosing. Thus, given the 6-month establishing period in this study, it is reasonable to assume that potential wash out of fines from the filters had already ceased before stormwater dosing and sampling was started. Further, leaching may also occur in the long term as organic material breaks down (Marvin et al. 2020). This was not observed in our study either which is most likely due to the relatively short time frame of our experiment compared with field sites, which are operated for several years. However, the filter material with relatively little organic content might mitigate extended wash out of organics and associated P to some extent, while dead vegetation cannot be avoided on bioretention if not removed regularly from the surface of the facility (Blecken et al. 2017).

As summarized in Sect. 1, various additives to enhance $\mathrm{P}$ removal in bioretention systems have been suggested (cf. Marvin et al. 2020). The need for these is not supported by the findings of this study given the very efficient $P$ removal observed. This coupled with the lack of wash out of fines shows that even relatively simple and cheap sand-based filter materials without specific additives can provide sufficient and reliable $\mathrm{P}$ treatment. This is in accordance with findings by, e.g., Blecken et al. (2010) and Glaister et al. (2017), who also used basic, sand-based filter material. However, given that our study was only a short time pilot-scale experiment, these suggestions should be verified in the field over longer time periods.

\section{Conclusions}

The effects of a submerged zone, temperature, and salinity and their interactions on bioretention $\mathrm{P}$ treatment performance were tested using column experiments. A relatively simple, sand-based filter material without any specific additives to enhance $\mathrm{P}$ removal was used. Temperature was found to be the main factor affecting $\mathrm{P}$ removal: high temperatures caused higher outflow concentrations and thus worsened removal. Salt also deteriorated TP removal, whereas DP removal was not affected. Despite being statistically significant, the impact of the SZC was not regarded to be of practical significance for P removal. In contrast, TSS removal was enhanced by a SZC. In general, despite the impact of the factors, the bioretention effluent contained far less $\mathrm{P}$ than the stormwater. This underlines that a sand-based filter material can provide excellent $P$ removal without the need for additives suggested in other studies. Longer-term experiments and verification in the field is recommended.

Acknowledgments Additionally, the authors wish to thank Kerstin Nordqvist, Karolina Berggren, Simon Viklander, and Camilla Westerlund for help prior to and during the experimental run.

Code Availability Not applicable

Author Contribution Godecke Blecken, Maria Viklander, and Laila Søberg contributed to the study conception and design. Material preparation, data collection, and analysis were performed by Laila Søberg, Godecke Blecken, and Ahmed Al-Rubaei. The first draft of the manuscript was written by Laila Søberg and Ahmed Al-Rubaei. Godecke Blecken was responsible for the revision of the manuscript. All authors commented on previous versions of the manuscript and the revision. All authors read and approved the final manuscript.

Funding Information Open access funding provided by Lulea University of Technology. The authors acknowledge financial support from the Swedish Research Council Formas (grant number 2010-787) for conducting the experiment and chemical analyses. Data analysis and paper writing were enabled by grants from the Swedish research council Formas (grant number 201620074) and VINNOVA (Swedish Governmental Agency for Innovation Systems), who provided financial support for DRIZZLE - Centre for Stormwater Management (grant number 201605176).Data AvailabilitySupplementary material

\section{Compliance with Ethical Standards}

Conflict of Interest The authors declare that they have no conflict of interest.

Open Access This article is licensed under a Creative Commons Attribution 4.0 International License, which permits use, sharing, adaptation, distribution and reproduction in any medium or format, as long as you give appropriate credit to the original author(s) and the source, provide a link to the Creative Commons licence, and indicate if changes were made. The images or other third party material in this article are included in the article's Creative Commons licence, unless indicated otherwise in a credit line to the material. If material is not included in the article's Creative Commons licence and your intended use is not permitted by statutory regulation or exceeds the permitted use, you will need to obtain permission directly from the copyright holder. To view a copy of this licence, visit http://creativecommons.org/licenses/by/4.0/. 


\section{References}

Bai, J., Ye, X., Jia, J., Zhang, G., Zhao, Q., Cui, B., \& Liu, X. (2017). Phosphorus sorption-desorption and effects of temperature, $\mathrm{pH}$ and salinity on phosphorus sorption in marsh soils from coastal wetlands with different flooding conditions. Chemosphere, 188, 677-688.

Barbosa, A. E., Fernandes, J. N., \& David, L. M. (2012). Key issues for sustainable urban stormwater management. Water Research, 46(20), 6787-6798.

Barrow, N. J. (1979). Three effects of temperature on the reactions between inorganic phosphate and soil. Journal of Soil Science, 30(2), 271-279.

Berretta, C., \& Sansalone, J. (2011). Speciation and transport of phosphorus in source area rainfall-runoff. Water, Air, and Soil Pollution, 222(1-4), 351-365.

Blecken, G.-T., Zinger, Y., Muthanna, T. M., Deletic, A., Fletcher, T. D., \& Viklander, M. (2007). The influence of temperature on nutrient treatment efficiency in stormwater biofilter systems. Water Science and Technology, 56(10), 83-91.

Blecken, G. T., Zinger, Y., Deletic, A., Fletcher, T. D., Hedström, A., \& Viklander, M. (2010). Laboratory study on stormwater biofiltration: nutrient and sediment removal in cold temperatures. Journal of Hydrology, 394(3-4), 507-514.

Blecken, G.-T., Hunt, W. F., Al-Rubaei, A. M., Viklander, M., \& Lord, W. G. (2017). Stormwater control measure (SCM) maintenance considerations to ensure designed functionality. Urban Water Journal, 14(3), 278-290.

Boström, B., Persson, G., \& Broberg, B. (1988). Bioavailability of different phosphorus forms in freshwater systems. Hydrobiologia, 170(1), 133-155.

Bratieres, K., Fletcher, T. D., Deletic, A., \& Zinger, Y. (2008). Nutrient and sediment removal by stormwater biofilters: a large-scale design optimisation study. Water Research, 42(14), 3930-3940.

Chahal, M. K., Shi, Z., \& Flury, M. (2016). Nutrient leaching and copper speciation in compost-amended bioretention systems. Science of the Total Environment, 556, 302-309.

Cheng, J., Yuan, Q., \& Kim, Y. (2018). Long-term operational studies of lab-scale pumice-woodchip packed stormwater biofilters. Environmental Technology (United Kingdom), 39(14), 1765-1775.

Correll, D. L. (1998). The role of phosphorus in the eutrophication of receiving waters: a review. Journal of Environmental Quality, 27(2), 261-266.

Davis, A. P., Shokouhian, M., Sharma, H., \& Minami, C. (2006). Water quality improvement through bioretention media: nitrogen and phosphorus removal. Water Environment Research, 78(3), 284-293.

Dietz, M. E., \& Clausen, J. C. (2005). A field evaluation of rain garden flow and pollutant treatment. Water, Air, and Soil Pollution, 167(1-4), 123-138.

Dietz, M. E., \& Clausen, J. C. (2006). Saturation to improve pollutant retention in a rain garden. Environmental Science and Technology, 40(4), 1335-1340.

Ding, B., Rezanezhad, F., Gharedaghloo, B., Van Cappellen, P., \& Passeport, E. (2019). Bioretention cells under cold climate conditions: effects of freezing and thawing on water infiltration, soil structure, and nutrient removal. Science of the Total Environment, 649, 749-759.
Erickson, A. J., Gulliver, J. S., \& Weiss, P. T. (2012). Capturing dissolved phosphorus with iron enhanced sand filtration. Water Research, 46(9), 3032-3042.

FAWB (2008). Facility for advancing water biofiltration. Advancing the Design of Stormwater Biofiltration.

Glaister, B. J., Fletcher, T. D., Cook, P. L. M., \& Hatt, B. E. (2017). Interactions between design, plant growth and the treatment performance of stormwater biofilters. Ecological Engineering, 105, 21-31.

Goonetilleke, A., Thomas, E., Ginn, S., \& Gilbert, D. (2005). Understanding the role of land use in urban stormwater quality management. Journal of Environmental Management, 74(1), 31-42.

Hatt, B. E., Fletcher, T. D., \& Deletic, A. (2009). Hydrologic and pollutant removal performance of stormwater biofiltration systems at the field scale. Journal of Hydrology, 365(3-4), 310-321.

Hsieh, C., \& Davis, A. P. (2005). Multiple-event study of bioretention for treatment of urban storm water runoff. Water Science and Technology, 51(3-4), 177-181.

Hsieh, C., Davis, A. P., \& Needelman, B. A. (2007). Bioretention column studies of phosphorus removal from urban stormwater runoff. Water Environment Research, 79(2), 177-184.

Hunt, W. F., Jarrett, A. R., Smith, J. T., \& Sharkey, L. J. (2006). Evaluating bioretention hydrology and nutrient removal at three field sites in North Carolina. Journal of Irrigation and Drainage Engineering, 132(6), 600-608.

Hunt, W. F., Davis, A. P., \& Traver, R. G. (2012). Meeting hydrologic and water quality goals through targeted bioretention design. Journal of Environmental Engineering (United States), 138(6), 698-707.

Iqbal, H., Garcia-Perez, M., \& Flury, M. (2015). Effect of biochar on leaching of organic carbon, nitrogen, and phosphorus from compost in bioretention systems. Science of the Total Environment, 521-522, 37-45.

Jun, M., Altor, A. E., \& Craft, C. B. (2013). Effects of increased salinity and inundation on inorganic nitrogen exchange and phosphorus sorption by tidal freshwater floodplain forest soils, Georgia (USA). Estuaries and Coasts, 36(3), 508-518.

Kratky, H., Li, Z., Chen, Y., Wang, C., Li, X., \& Yu, T. (2017). A critical literature review of bioretention research for stormwater management in cold climate and future research recommendations. Frontiers of Environmental Science \& Engineering, 11(4), 16.

Lau, Y. L., Marsalek, J., \& Rochfort, Q. (2000). Use of a biofilter for treatment of heavy metals in highway runoff. Water Quality Research Journal of Canada, 35(3), 563-580.

Li, J., \& Davis, A. P. (2016). A unified look at phosphorus treatment using bioretention. Water Research, 90, 141-155.

Li, M.-H., Swapp, M., Kim, M. H., Chu, K.-H., \& Sung, C. Y. (2014). Comparing bioretention designs with and without an internal water storage layer for treating highway runoff. Water Environment Research, 86(5), 387-397.

Li, J., Liang, Z., Li, Y., Li, P., \& Jiang, C. (2018). Experimental study and simulation of phosphorus purification effects of bioretention systems on urban surface runoff. PLoS One, 13(5).

Liu, M., Hou, L., Xu, S., Ou, D., Yang, Y., Zhang, B., \& Liu, Q. (2002). Adsorption of phosphate on tidal flat surface 
sediments from the Yangtze Estuary. Environmental Geology, 42(6), 657-665.

Mangangka, I. R., Liu, A., Egodawatta, P., \& Goonetilleke, A. (2015). Performance characterisation of a stormwater treatment bioretention basin. Journal of Environmental Management, 150, 173-178.

Marvin, J. T., Passeport, E., \& Drake, J. (2020). State-of-the-art review of phosphorus sorption amendments in bioretention media: a systematic literature review. Journal of Sustainable Water in the Built Environment, 6(1). https://doi.org/10.1061 /JSWBAY.0000893.

McManus, M., \& Davis, A. (2017). Impact of periodic high concentrations of salts on bioretention nutrients performance. In Proceedings of the 14th International Conference on Urban Drainage, Prague, September 10th to 15th.

Mucci, M., Maliaka, V., Noyma, N. P., Marinho, M. M., \& Lürling, M. (2018). Assessment of possible solid-phase phosphate sorbents to mitigate eutrophication: influence of $\mathrm{pH}$ and anoxia. Science of the Total Environment, 619-620, 1431-1440.

Nürnberg, G. K. (1984). The prediction of internal phosphorus load in lakes with anoxic hypolimnia. Limnology and Oceanography, 29(1), 111-124.

Passeport, E., Hunt, W. F., Line, D. E., Smith, R. A., \& Brown, R. A. (2009). Field study of the ability of two grassed bioretention cells to reduce storm-water runoff pollution. Journal of Irrigation and Drainage Engineering, 135(4), 505-510.

Reddy, K. R., \& DeLaune, R. D. (2008). Biogeochemistry of wetlands: science and applications. Boca Raton: CRC Press.

Remmen, K., Niewersch, C., Wintgens, T., Yüce, S., \& Wessling, M. (2017). Effect of high salt concentration on phosphorus recovery from sewage sludge and dewatering properties. Journal of Water Process Engineering, 19, 277-282.

Søberg, L. C., Viklander, M., \& Blecken, G.-T. (2017). Do salt and low temperature impair metal treatment in stormwater bioretention cells with or without a submerged zone? Science of the Total Environment, 579, 1588-1599.

Szota, C., Farrell, C., Livesley, S. J., \& Fletcher, T. D. (2015). Salt tolerant plants increase nitrogen removal from biofiltration systems affected by saline stormwater. Water Research, 83, 195-204.

Valtanen, M., Sillanpää, N., \& Setälä, H. (2017). A large-scale lysimeter study of stormwater biofiltration under cold climatic conditions. Ecological Engineering, 100, 89-98.

Walsh, C. J., Roy, A. H., Feminella, J. W., Cottingham, P. D., Groffman, P. M., \& Morgan II, R. P. (2005). The urban stream syndrome: current knowledge and the search for a cure. Journal of the North American Benthological Society, 24(3), 706-723.

Winston, R. J., Davidson-Bennett, K. M., Buccier, K. M., \& Hunt, W. F. (2016). Seasonal variability in stormwater quality treatment of permeable pavements situated over heavy clay and in a cold climate. Water, air, and soil pollution, 227 (5).

Yang, Y., \& Toor, G. S. (2018). Stormwater runoff driven phosphorus transport in an urban residential catchment: implications for protecting water quality in urban watersheds. Scientific Reports, 8(1).

Zhang, J., \& Huang, X. (2011). Effect of temperature and salinity on phosphate sorption on marine sediments. Environmental Science and Technology, 45(16), 6831-6837.

Zhang, W., Brown, G. O., \& Storm, D. E. (2008). Enhancement of heavy metals retention in sandy soil by amendment with fly ash. Transactions of the ASABE, 51(4), 1247-1254.

Zhang, Z., Rengel, Z., Liaghati, T., Antoniette, T., \& Meney, K. (2011). Influence of plant species and submerged zone with carbon addition on nutrient removal in stormwater biofilter. Ecological Engineering, 37(11), 1833-1841.

Zhao, L., \& Gray, D. M. (1999). Estimating snowmelt infiltration into frozen soils. Hydrological Processes, 13(12-13), 1827 1842.

Zinger, Y., Blecken, G. T., Fletcher, T. D., Viklander, M., \& Deletic, A. (2013). Optimising nitrogen removal in existing stormwater biofilters: benefits and tradeoffs of a retrofitted saturated zone. Ecological Engineering, 51, 75-82.

Publisher's Note Springer Nature remains neutral with regard to jurisdictional claims in published maps and institutional affiliations. 